\title{
Teaching of Remote Sensing Technology for Landscape Architecture in the Context of Spatial Information Technology
}

\author{
https://doi.org/10.3991/ijet.v16i15.24885 \\ Xueling Zhang, Dayu Zhang \\ Beijing University of Civil Engineering and Architecture, Beijing, China \\ zhangdayu@bucea. edu.cn
}

\begin{abstract}
The research of digital landscape architecture springs up in recent years. The emerging digital technology provides a rational and objective method to mine and quantify the endogenous laws of landscape architecture. Remote sensing (RS) technology has become a new growth point in the current research and design of landscape spatial information. To develop the professional teaching of landscape architecture, it is important to fully integrate the RS technology into the teaching system of spatial information technology, carry out systematic spatial information quantification and research-based teaching of landscape architecture, and collaboratively promote the teaching of landscape architecture design. This paper firstly analyzes the integration and application potential of RS technology into landscape architecture. Considering the demand and trend of information-based teaching of landscape architecture, the authors integrated the relevant technologies into an RS teaching platform for landscape architecture, and summarized an application model of RS technology in the teaching of landscape architecture theories and practices. Moreover, a landscape spatial information chain, which is question-oriented, task-driven, and exploration-based, was constructed to promote the synergistic development between the students' research and practice ability under spatial information integration.
\end{abstract}

Keywords—spatial information technology, remote sensing (RS) technology, teaching platform, course practice, landscape architecture

\section{Introduction}

The research of digital landscape architecture springs up in recent years. The emerging digital technology provides a rational and objective method to mine and quantify the endogenous laws of landscape architecture, making the landscape architecture research much more scientific and efficient. Spatial information technology has quickly permeated every aspect of the teaching, scientific research, and engineering of landscape architecture [1-10]. Representative spatial information techniques, including remote sensing (RS), spatial big data, earth observation monitoring, and spatial positioning and simulation, directly drive the synergistic development between the teaching of $\mathrm{RS}$ in landscape architecture and the teaching of landscape architecture design, and 
stimulate the continued breakthroughs and innovations of relevant teaching platforms, methods, and experimental means [11]. Suffice it to say that spatial information technology offers an important tool to tap the development potential and improve the teaching quality of landscape architecture.

The new round of industrial revolution has brought new opportunities and challenges in higher education. The new technologies, industries, and development trends give birth to the conceiving-designing-implementing-operating (CDIO) model for engineering teaching, which satisfies the latest demand for professional talents [12]. The core of CDIO is curriculum reform. Compared with traditional teaching mode, CDIO curriculum reform aims to break traditional professional barriers, renovate learning methods, and understand the knowledge and logic behind through practice and research, and abide by the cognition law of professional learning [13].

Against this backdrop, the authors deeply analyzed and judged the advantages and trends of contemporary spatial information technology. Inspired by interdisciplinary applied teaching systems, this paper pursues integrated development and technological cooperation of the teaching of RS in landscape architecture through curriculum reform and innovative teaching module design, and synthetizes relevant technologies into an RS teaching platform for landscape architecture. Besides, a research and learning model, which is question-oriented, task-driven, and exploration-based, was constructed for landscape spatial information. The proposed model can promote the synergistic development between the students' research and practice ability under spatial information integration [14], and facilitate the RS teaching reform of landscape architecture.

\section{Industrial Application of Spatial Information Technology in Landscape Architecture}

The spatial information technology of landscape architecture is highly integrated with multiple disciplines. It is an enhanced digital technology capable of collecting, processing, managing, analyzing, expressing, communicating, and applying landscape information. In the field of landscape architecture, many modern technologies are deeply combined, including spatial technology, sensor technology, satellite positioning and navigation technology, and computational analysis [15]. RS technology provides landscape architecture with the easiest way of earth observation monitoring, and a forceful tool to analyze landscape environment information.

Thanks to the rapid development of spatial information technology and the civilian use of high-space, high-resolution earth observation monitoring, RS technology can now monitor a wide range of the earth surface, and collect a huge number of positioning and quantification data in a real time and accurate manner. The technology makes it possible to expand the information platform for landscape survey, assessment and control, discover the quantitative law of landscape architecture at different scales, and improve the technology level of landscape architecture [16].

Meanwhile, RS technology can satisfy the demand for resource surveys and special drawings of various landscapes, and assist with landscape architecture design, according to the purposes of learning and research. In this way, RS technology provides a 
strong technical support for contemporary landscape architecture research and practice [17]. At present, landscape RS is widely applied in the landscape architecture industry to survey landscape resources, extract information, and implement dynamic monitoring.

\subsection{Landscape resource survey}

From the perspective of landscape architecture, landscape resource refers to the collection and statistical analysis of natural resources or landscape environments, and to formation of professional judgments [18]. Since the 1980s, aerial RS images have gradually been introduced to landscape survey and analysis. The relevant survey data lay the basis for landscape architecture research and design. The survey method and technology have become an important part of the knowledge system for landscape architecture.

With the continuous improvement of spatial information analysis technology, highresolution RS images, which are rich in geometric features and texture information, expand the scope and depth of landscape survey. Currently, spatial information analysis technologies like eCognition can comprehensively interpret landscape images based on the spectrum, texture, spatial structure, and geometry, providing an effective solution to the following traditional problems: it is inefficient and inaccurate to interpret the high-resolution landscape images containing multi-source data [19]. As a result, objectoriented information extraction techniques have created the main application path for the landscape architecture industry (see Table 1).

Table 1. Main contents of landscape resource survey with spatial information analysis technology

\begin{tabular}{|l|l|l|}
\hline \multirow{5}{*}{ Natural elements } & Vegetation & $\begin{array}{l}\text { Vegetation communities and morphology, trees, shrubs, ground } \\
\text { covers, aquatic plants, etc. }\end{array}$ \\
\cline { 2 - 3 } & Terrain & $\begin{array}{l}\text { Land and surface water distribution, elevation, slope, slope, catch- } \\
\text { ment surface, etc. }\end{array}$ \\
\cline { 2 - 3 } Artificial elements & Hydrology & $\begin{array}{l}\text { Water body form, water depth, water quality, aquatic plant distri- } \\
\text { bution, etc. }\end{array}$ \\
\cline { 2 - 3 } & Soil & $\begin{array}{l}\text { Bare soil quality, soil type, mountain surface rock distribution and } \\
\text { type, etc. }\end{array}$ \\
\cline { 2 - 3 } & Historical remains & $\begin{array}{l}\text { Historical remains identification and discovery, morphological fea- } \\
\text { tures, material and color, etc. } \\
\text { struction quality, etc. }\end{array}$ \\
\hline \multirow{3}{*}{$\begin{array}{l}\text { Environmental } \\
\text { conditions }\end{array}$} & Roads & $\begin{array}{l}\text { Road distribution, road width, construction condition, road mate- } \\
\text { rial, etc. }\end{array}$ \\
\cline { 2 - 3 } & $\begin{array}{l}\text { Construction con- } \\
\text { ditions }\end{array}$ & $\begin{array}{l}\text { Land type, artificial facility distribution, construction activities, } \\
\text { etc. }\end{array}$ \\
\hline
\end{tabular}

\subsection{Landscape information extraction}

Landscape information extraction from RS images is an effective way to analyze and grasp the current state and dynamic changes of landscape environment. With the aid of 
superior spatial information analysis technology, single landscape elements can be recognized automatically and extracted by class, e.g., urban green space, urban buildings, scenic vegetation, water body, roads, etc. The landscape information can also be extracted from large-scale landscape environments with complex and diverse landscape patterns [20], such as river basins, mountainous terrains, mountain lakes, and surface covers. These landscape patterns involve landscape types like urban green space, wetland, farmland, forest, and scenic spots.

Since spatial information technology has advantages in landscape image processing, multi-source data analysis, vegetation physiological features identification, and topological geometry analysis, RS technology gradually forms an effective way to cope with the current demand for spatial information of landscape architecture, in both vertical and horizontal dimensions [21]. The core RS techniques, namely, machine learning and deep learning, have been subjected to cross-application, providing important technical support for the intelligent, quantitative, and information-based development of landscape architecture, and opening an innovative path towards the digital and scientific teaching of landscape architecture.

\subsection{Landscape dynamic monitoring}

The landscape is defined as a multi-scale geospatial unit that dynamically and comprehensively comprises human landscape elements and natural landscape elements. Landscape monitoring aims to analyze the composition and spatial configuration of the target landscape. The main functions of landscape monitoring include detecting the changes in landscape pattern, capturing the situation and problems of landscape development in time, and forecasting the trend and law of landscape pattern [22]. From static monitoring to continuous dynamic monitoring, landscape dynamic monitoring effectively collects the dynamics of the landscape systems from the small local scale to the large national scale [23], including urban landscape system, agricultural landscape system, forest landscape system, wetland landscape system, as well as grassland and desert landscape system.

Whereas digital landscape and digital cities are key aspects of living environment construction, spatial information technology offers a golden opportunity for the development of digital technology for landscape architecture, and provides the following works with a technical system and an operation platform: building a landscape environmental information system integrating knowledge update, technological innovation, and data drivers; promoting the application of RS monitoring, Internet of things (IoT), and big data in the survey, analysis, design, control, and operation maintenance of landscape architecture; speeding up the construction of information application system for eco-protection and repair [24]. 


\section{Application of RS Technology in Landscape Architecture Teaching}

Currently, professional colleges of landscape architecture in most developed countries have opened courses on landscape information technology, and gradually increased the class hours and credits of these courses. Harvard University and Technische Universität Wien have event replaced landscape engineering technology courses with landscape information technology courses. The $3 \mathrm{~S}$ technology is the main teaching content of landscape information technology. It is a collective name for RS, geographic information system (GIS), and global navigation satellite system (GNSS) [25]. Most colleges agree that landscape architecture should be taught with GIS as the core, supplemented by RS and big data technology.

\subsection{Features of RS teaching in landscape architecture}

Clear professional demand and technical requirements: In landscape architecture colleges, the RS courses generally focus on the professional features of quantitative study on ecology and form of landscape environment [26]. The course teaching has distinctive professional features. The teaching contents are driven by regional features, local environment, surface resources, land space utilization, and auxiliary planning and design.

Meanwhile, the contemporary research of landscape architecture raises a high requirement on the extraction of spatial information and analytical elements. The traditional identification and definition of surface landscape elements can no longer satisfy the needs of modern landscape architecture and design. Apart from mastering the extraction technology for salient elements of RS images, the students need to learn the deep analysis and algorithm parsing of image data. Professional problems like landscape features, landscape form, blue-green landscape coupling call for the assistance from spatial information technology, and the evolution from shallow element recognition to composite parsing. Therefore, the in-depth exploration of analytical technology is more compatible with professional demand than simple applications [27].

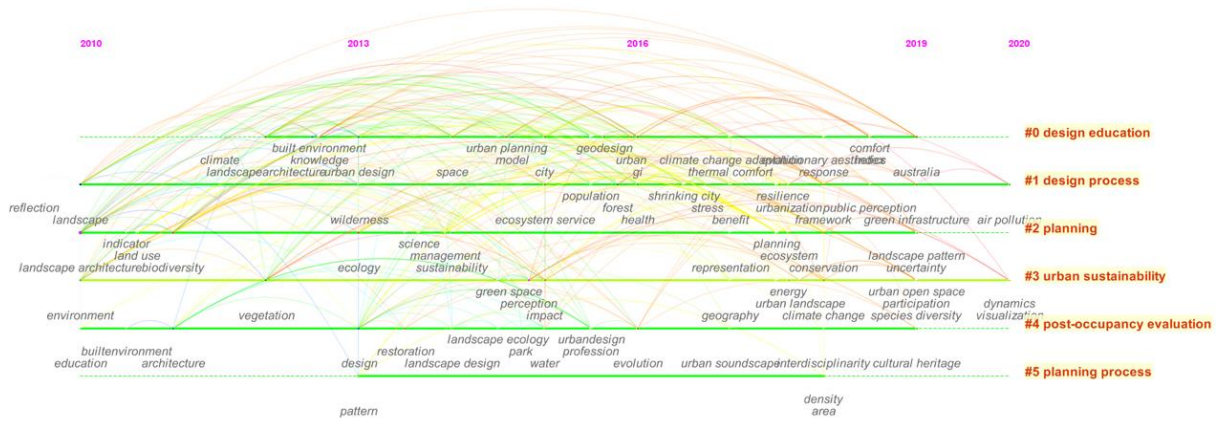

Fig. 1. Key application fields of RS for landscape architecture provided by Web of Science (Cite Space data analysis) 
Comprehensive knowledge structure and integration between theory and practice: The contemporary RS teaching for landscape architecture requires comprehensive use of the basic knowledge in measurement, cartography, RS, geography, botany, and hydrology. As spatial information technology injects new vitality into the development of landscape architecture, many scientific fields are urgently in need of this technology: plant landscape and habitat diversity protection, urban and rural green space systems, planning and design theories and methods, ecological technology and green infrastructure, landscape engineering and technology, landscape architecture history and heritage (see Figure 1) [28]. Therefore, teachers must pay equal attention to the basic concepts and theories of the relevant disciplines, and focus on the scientific issues and practical needs of landscape architecture. They should try to fully cover the basic principles, software, theories, cases, and practices in a limited teaching time.

\subsection{Main problems in RS teaching of landscape architecture}

Right now, the research scope of landscape architecture is quickly expanding. However, the research of the interaction between natural and human systems has just started. The class hours and credits of landscape architecture in higher education are not yet sufficient to meet the requirements of the teaching standard. Against this backdrop, the core issue of innovative development of courses on landscape spatial information technology is to improve quality and increase efficiency [29]. The main problems in RS teaching of landscape architecture are as follows:

(1) The curriculum system needs to be optimized, and the teaching model is yet to be innovated.

In the heavy presence of living environment, the issues of landscape architecture, from basic theories to application technologies, cannot be effectively handled without scientific methods from multiple disciplines. If the teaching goals and methods are unclear, the problems will not be pinpointed, the solutions will not be suitable, and the professional analysis will not be logic.

(2) Empirical research is badly needed for the construction of information technology teaching platform.

The lack of digital teaching platform bottlenecks the teaching and research of landscape architecture, and constrains many teachers and researchers in the study. They should carry out empirical research driven by realistic problems, fully integrate experiments with practices. Due to the deficiency in empirical research, the frontier knowledge cannot quickly enter the classroom, which affects the quality of learning and design.

(3) Key knowledge points must be scientifically condensed, and the synergy with design courses is to be improved.

The landscape architecture technology courses generally lack class hours. It is difficult to teach so many contents in a limited amount of time. To solve the problem, the preferred way is to highlight the key knowledge in the short period, and implement autonomous research and learning through organic integration with design courses. 


\section{Trend of RS Teaching for Landscape Architecture}

The emerging spatial information technology provides a new information-based digital analysis pathway and operation platform for professional landscape architecture teaching in the context of CDIO. Considering the cultivation goals of student abilities and industrial demand, the main trend of RS teaching for landscape architecture is to integrate and analyze RS and other spatial information analysis technologies, take capacity improvement as the goal of research and learning, and combine the landscape spatial information knowledge into a data chain and a logic chain, which are questionoriented, task-driven, and exploration-based [30], with the goal to maximize the system effect.

In addition, the teachers of landscape spatial information technology should fully integrate theoretical teaching with practical teaching, and highlight the integrated use of spatial information technology in landscape architecture design. Furthermore, special attention should be paid to the fact that RS technology, operating system, and highdefinition image data have completed technological updates in recent years, making it imminent to renovate the teaching contents and research/learning model of RS.

\section{Architecture of RS Teaching Platform for Landscape Architecture}

RS teaching is a crucial part of information engineering teaching in landscape architecture. To cultivate research talents under the CDIO model, it is important to improve the following abilities of students: application of aerial RS images to landscape environment analysis, professional design and management, as well as application and innovation. The course teaching should focus on the analysis of realistic problems, the building of RS technology application environment, and the creation of real-world scenarios [31]. As a result, this paper attempts to clarify the logical relationship between the basic layer, data layer, support layer, application layer and interactive layer of the RS teaching platform for landscape architecture.

(1) Basic layer

The platform adopts the browser/server (B/S) structure to ensure good compatibility. The basic layer is responsible for building computing resources, storage resources, and network resources. The components of this layer include core switches, network management and security devices, RS data servers, and RS data storage devices.

(2) Data layer

This layer mainly encompasses high-definition aerial RS image data, aerial data, and related vector data, raster data, internal management data, etc. These data can be generally split into structural resources and non-structural resources. By effective classification of the database, this layer establishes a complete metadata on teaching management, and makes efficient management and use of shared data.

(3) Support layer

Lying between the data layer and the application layer, the support layer covers image storage standards, data reception and processing flow, data stream control system, 
and information formation. To allow students to autonomously carry out experiments, research, and learning on terminals, the support layer also integrates virtual computing, relational database system, and object database system, creating a software environment necessary for data sharing.

(4) Application layer

This layer is responsible for remote teaching and data distribution, query and download management of RS data, as well as acquisition and checking of terminal landscape learning results. The main components are various teaching applications like query and search, application and distribution, data management, factor extraction, and verification of complex results.

(5) Interactive layer.

This layer enables teacher-student interaction through dialog boxes. Online video interaction module can be added to achieve remote learning, in addition to classroom teaching. On this layer, the released topic can be decomposed into multiple sub-topics, and the students can learn the sub-topics through collaboration. This effectively broadens and deepens the scope of teaching.

\section{$6 \quad$ RS Teaching System and Curriculum Construction for Landscape Architecture}

\subsection{Setting teaching goals and class hours}

Overall, the spatial information of landscape architecture is featured by the integration and complementation between multiple disciplines, the interaction and organic permeation between landscape space elements, and the comprehensive utilization of learning and practice of landscape architecture design [32]. Therefore, 3S integrated teaching should be pursued rather than setting up independent courses. The landscape spatial information technology and method should be taught in a -oriented, task-driven, and exploration-based model, reflecting the demand of professionals of landscape architecture. The primary stage is manifested as the coordination between functions, which highlights the correlations between analysis systems. The advanced stage is manifested by the collaboration between functions to dynamically update the analysis data, and to support real-time query, analysis, and judgment right on the spot.

Therefore, the RS teaching for landscape architecture should be guided by the demand for landscape architecture analysis and research. After mastering the basic knowledge of spatial information on landscape and environment, the students should get familiar with the common preprocessing algorithms and professional software for RS image data, propose RS interpretation pathways for different landscape environmental resources [33], and complete information acquisition and accuracy evaluation of the topic through practice.

In terms of practical ability, the students are required to carry out landscape architecture resource surveys, make analysis decision-making on landscape architecture, and 
prepare special drawings to assist with landscape architecture design [34]. The drawings should have a good visual effect, with a proper scale, suitable elements, and right configuration.

In terms of overall quality, the students should logically implement their scientific thoughts on spatial information to landscape architecture design, acquire innovative awareness and independent learning ability, and excel in independent research and development as well as teamwork.

Considering the overall teaching contents of landscape architecture spatial information, it is recommended to reasonably configure the modules of the teaching system, namely, introduction module, GIS module, RS module, and GNSS module. The class hours for course teaching should not be shorter than 64, including 32 for undergraduate stage and 32 for graduate stage. An equal amount of class hours should be arranged for autonomous research/learning and design/application. Therefore, the total class hours amount to 192 . Specifically, the RS teaching should at least cover 48 class hours (at least 16 for classroom teaching). The teaching plan and class hours should be designed and allocated for the following contents: basic principles of RS, object-oriented classification mechanism, interpretation of natural environment landscape, interpretation of artificial environment landscape (see Figure 2).

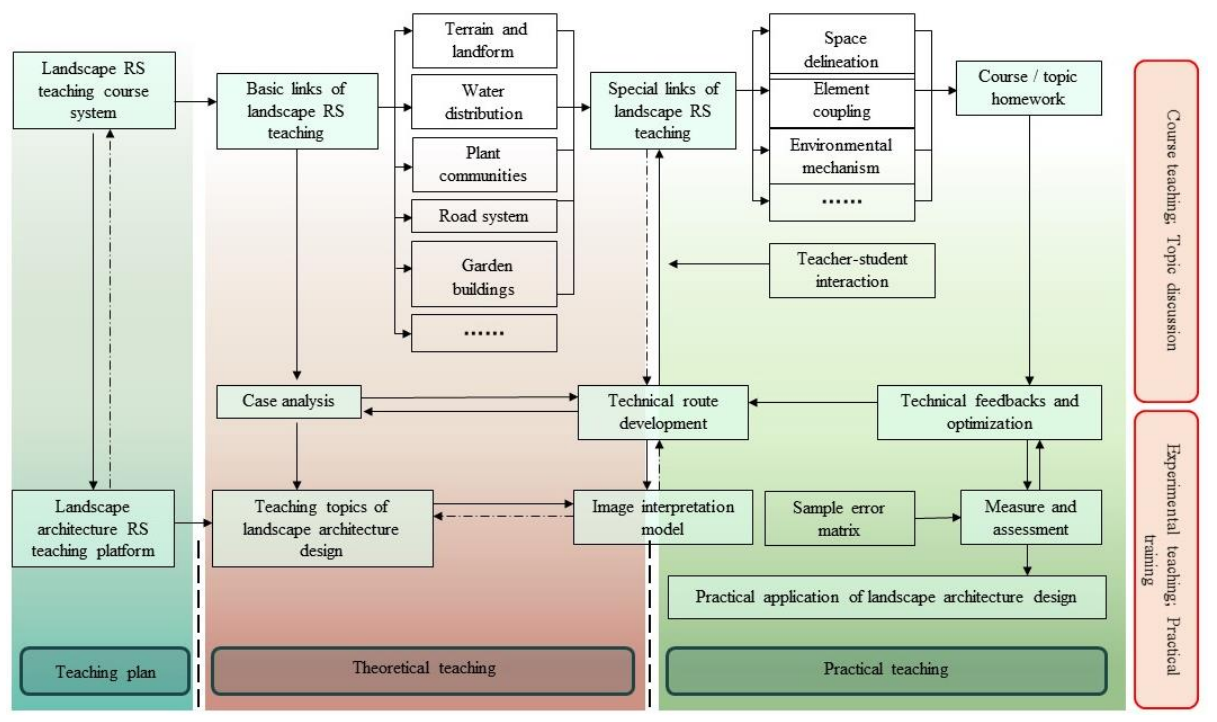

Fig. 2. RS teaching contents of landscape architecture

\subsection{Theoretical teaching}

The theoretical teaching of RS for landscape architecture mainly covers the following contents:

(1) Basic principles of RS 
This part mainly includes overview and current progress of RS applications in landscape architecture, principles of RS electromagnetic radiation, RS data sources, principles and processing methods of image interpretation, and comprehensive data analysis methods. The theoretical teaching needs 2 class hours (undergraduate stage).

(2) Object-oriented classification mechanism

This part mainly includes general simplified processes of image preprocessing, and principles, methods and operational techniques of object-oriented classification principles. To enable the students to quickly master the basic methods, the teachers need to explain the common and universal technical modules for landscape architecture. The theoretical teaching needs 2 class hours (undergraduate stage).

(3) Interpretation of natural environment landscape

This part mainly includes the methods and technologies for RS recognition, extraction, single factor analysis, and composite analysis of natural landscape elements. The recognition of landscape elements should reach the level of plant varieties [35]. The theoretical teaching needs 6 class hours ( 2 for undergraduate stage; 4 for graduate stage).

(4) Interpretation of artificial environment landscape

This part mainly includes the methods and technologies for RS recognition, extraction, single factor analysis, and composite analysis of artificial landscape elements. The recognition of landscape elements should reach the level of single building contours. For top students, the teaching contents can be expanded to the basic principles and methods of RS monitoring, as well as the latest RS data and analysis methods (e.g., nightlights) [36]. The theoretical teaching needs 6 class hours ( 2 for undergraduate stage; 4 for graduate stage).

\subsection{Practical teaching}

Practical teaching is an effective way to consolidate the theoretical knowledge on $\mathrm{RS}$, deepen the understanding of landscape architecture, and further improve the relevant operations. It is an important link in the cultivation of innovative, high-quality landscape architecture researchers and designers. The practical teaching can be divided into autonomous research/learning and design/application. These two parts should be assigned an equal amount of class hours as theoretical teaching. Besides, four topics should be designed, namely, RS sign interpretation and field research, feature identification and quantification of landscape objects, information extraction from natural environmental landscape, and information extraction from artificial environmental landscape [37]. The latter two topics can be flexibly arranged in combination with the topics of design courses.

Despite difficulties in teaching management and the consistency between teaching effect and standard, practical teaching, if properly implemented, can achieve more significant effect than theoretical teaching, especially on the student abilities of active exploration and learning. Therefore, the teaching activities should be designed more extensively and flexibly in conjunction with the collaboration between enterprises, universities and research institutes, engineering practice, design competition, and Summer Research Trainee Program (SRTP). 


\section{Conclusions}

The RS courses are an integral part of spatial information technology courses for landscape architecture. To maintain the vigor and vitality of these courses and promote the development of landscape architecture teaching, it is critical to adhere to the CDIO requirements on talent training, scientifically achieve theoretical teaching efficiency, give full play to practical teaching potential [38], and cleverly apply spatial information analysis methods and RS technology to reform the teaching of landscape information technology and construct the relevant courses.

Based on the teaching needs and development trend of information-based landscape architecture, this paper fully integrates the related technologies into an RS teaching platform for landscape architecture, and develops innovative practices that are questionoriented, task-driven, and exploration-based. The proposed method can greatly improve the research and practice abilities of the students, and consolidate their understanding and mastery of scientific knowledge and laws, so that they could make flexible use of the knowledge of multiple disciplines. In other words, our method helps to lay a solid foundation for cultivating new leaders for landscape architecture.

\section{Acknowledgment}

I thank Yanfeng Li, Xuehua Li, Xiaoyong Lv, Zhenwei Zhang and my colleagues in Beijing Advanced Innovation Center for Future Urban Design for their indispensable help with this research, I also thank for the effective support from Beijing Satlmage Information Technology Co., Ltd. The authors are grateful to the reviewers and the editors for the time and effort they put into their detailed comments that helped improve this paper.

This research is supported by the National Natural Science Foundation of China (Grant No. 51938002).

The authors declare that the research was conducted in the absence of any commercial or financial relationships that could be construed as a potential conflict of interest.

\section{$9 \quad$ References}

[1] Bada, S.O., Olusegun, S. (2015). Constructivism learning theory: A paradigm for teaching and learning. Journal of Research \& Method in Education, 5(6): 66-70. https://doi.org/10.9790/7388-05616670

[2] Wang, Y., Yu, Y., You, S.H., Lin, Y. (2020). Public landscape design for residential neighborhood in coastal areas. Environmental and Earth Sciences Research Journal, 7(4), 175-180. https://doi.org/10.18280/eesrj.070408

[3] Moussa, R.R., Dewidar, K.M. (2020). Energy-scape web-based application is an effective tool to overcome the basic knowledge of architects toward renewable energy properties. International Journal of Emerging Technologies in Learning, 15(10), 42-54. https://doi.org/10.3991/ijet.v15i10.13669 
Paper-Teaching of Remote Sensing Technology for Landscape Architecture in the Context of Spatial ...

[4] Li, Z., Han, X., Wang, L.Y., Zhu, T.Y., Yuan, F.T. (2020). Feature extraction and image retrieval of landscape images based on image processing. Traitement du Signal, 37(6), 10091018. https://doi.org/10.18280/ts.370613

[5] Lv, S.D., Pan, Y.J. (2020). Research on the spatial distribution difference of compulsory education between China and Australia. International Journal of Emerging Technologies in Learning, 15(4), 129-141. https://doi.org/10.3991/ijet.v15i04.11702

[6] Salih, M.M. (2021). Developing spectral reflectance measurement system for environmental remote sensing applications. International Journal of Design \& Nature and Ecodynamics, 16(1), 33-39. https://doi.org/10.18280/ijdne.160105

[7] Raju, M.N., Natarajan, K., Vasamsetty, C.S. (2021). Object recognition in remote sensing images based on modified backpropagation neural network. Traitement du Signal, 38(2), 451-459. https://doi.org/10.18280/ts.380224

[8] Daful M.G., Ezeamaka C.K., Ogbole M., Sani H., Sadiq Q.O. (2019). The application of remote sensing and geographic information system in assessing probable tsetse flies habitats in Ikom LGA, cross river state, Nigeria, Environmental and Earth Sciences Research Journal, 6(1), 19-23. https://doi.org/10.18280/eesrj.060103

[9] Rodríguez, Y.A., Pérez, Y.P., Roa, L.V., Jiménez-Rodríguez, C., Granda-Rodríguez, H.D., De Luque-Villa, M. (2020). Spatio-temporal analysis of forest fragmentation in Río Botello Catchment at Facatativá (Colombia). International Journal of Sustainable Development and Planning, 15(8), 1169-1178. https://doi.org/10.18280/ijsdp.150803

[10] Onyango, D.O., Ikporukpo, C.O., Taiwo, J.O., Opiyo, S.B. (2021). Land use and land cover change as an indicator of watershed urban development in the Kenyan Lake Victoria Basin. International Journal of Sustainable Development and Planning, 16(2), 335-345. https://doi.org/10.18280/ijsdp.160213

[11] Zhang, X.L. (2018). Practice teaching of landscape survey course based on eCognition remote sensing image interpretation* technology. Educational Sciences: Theory \& Practice, 18(5): 1411-1423. https://doi.org/10.12738/estp.2018.5.038

[12] Albanese, M.A., Mitchell, S. (1993). Problem-based learning: A review of literature on its outcomes and implementation issues. Academic Medicine-Philadelphia, 68(1): 52-81. https://doi.org/10.1097/00001888-199301000-00012

[13] Zhang, X.L., Li, Z., Li, D., He, Y.K. (2019). Marine environment distinctions and change law based on eCongnition remote sensing technology. Journal of Coastal Research, 94(SI): 107-111. https://doi.org/10.2112/SI94-020.1

[14] Dziob, D., Krupiński, M., Woźniak, E., Gabryszewski, R. (2020). Interdisciplinary Teaching Using Satellite Images as a Way to Introduce Remote Sensing in Secondary School. Remote Sensing, 12(18): 2868. https://doi.org/10.3390/rs12182868

[15] Shen, H.F., Li, H.F., Zeng, C., Li, Q., Huang, Q., Wu, C., Zhang, H.Y. (2021). Design of teaching contents for introduction to remote sensing under large category cultivation mode. Bulletin of Surveying and Mapping. (1):148-151. https://doi.org/10.13474/j.cnki.11$\underline{2246.2021 .0028}$

[16] Barron, B.J., Schwartz, D.L., Vye, N.J., Moore, A., Petrosino, A., Zech, L., Bransford, J.D. (1998). Doing with understanding: Lessons from research on problem-and project-based learning. Journal of the learning sciences, 7(3-4): 271-311. https://doi.org/10.1080/ 10508406.1998.9672056

[17] Li, Z., Han, X., Lin, X., Lu, X. (2021). Quantitative analysis of landscape efficacy based on structural equation modelling: Empirical evidence from new Chinese style commercial streets. Alexandria Engineering Journal, 60(1): 261-271. https://doi.org/10.1016/ j.aej.2020.08.005

[18] Sun, H., Cui, X.M., Yuan, D.B., Jiang, J.B., Sun, W.B. (2020). Exploring and practicing of 
Paper-Teaching of Remote Sensing Technology for Landscape Architecture in the Context of Spatial ...

effective teaching methods for quantitative remote sensing courses. Bulletin of Surveying and Mapping, (7): 147-151. https://doi.org/10.13474/j.cnki.11-2246.2020.0233

[19] He, X., Hua, X., Montillet, J.P., Yu, K., Zou, J., Xiang, D., Zhu, H.P., Zhang, D., Huang, Z.K., Zhao, B.F. (2019). An Innovative virtual simulation teaching platform on digital mapping with unmanned aerial vehicle for remote sensing education. Remote Sensing, 11(24): 2993. https://doi.org/10.3390/rs11242993

[20] Aina, Y.A., Aleem, K.F., Hasan, M. M., AlGhamdi, H., Mohamed, A. (2014). Geomatics education in the face of global challenges-A Saudi Arabian case study. Surveying and Land Information Science, 73(2), 81-90.

[21] Foresman, T.W., Cary, T., Shupin, T., Eastman, R., Estes, J.E., Faust, N., Jensen, J.R., Kemp, K.K. (1997). Internet teaching foundation for the Remote Sensing Core Curriculum program. ISPRS journal of photogrammetry and remote sensing, 52(6): 294-300. https://doi.org/10.1016/S0924-2716(97)00025-7

[22] Gorelick, N., Hancher, M., Dixon, M., Ilyushchenko, S., Thau, D., Moore, R. (2017). Google Earth Engine: Planetary-scale geospatial analysis for everyone. Remote sensing of Environment, 202: 18-27. https://doi.org/10.1016/j.rse.2017.06.031

[23] He, X.X., Lu, T.D., Li, C.C. (2018). Exploration on talents training pattern of Surveying and Mapping Engineering under the background of Excellent Engineer Program. Engineering of Surveying and Mapping. 27(1): 77-80.

[24] Schuettler, T., Maman, S., Girwidz, R. (2019). Teaching remote sensing techniques with high-quality, low-cost sensors [Education]. IEEE Geoscience and Remote Sensing Magazine, 7(2): 185-190. https://doi.org/10.1109/MGRS.2018.2878596

[25] Li, Z., Cheng, Y., Yuan, Y. (2018). Research on the application of virtual reality technology in landscape design teaching. Educational Sciences: Theory \& Practice, 18(5): 1400-1410. https://doi.org/10.12738/estp.2018.5.037

[26] Duffield, J.A., Grabinger, S., Dunlap, J.C. (1997). Rich environments for active learning in action: Problem-based learning. ALT-J. 5(2): 5-17. https://doi.org/10.1080/09687769 70050202

[27] Isaacson, S., Schüttler, T., Cohen-Zada, A.L., Blumberg, D.G., Girwidz, R., Maman, S. (2017). Sensing our environment: Remote sensing in a physics classroom. In EGU General Assembly Conference Abstracts. 19: 7158.

[28] Nijland, W., De Jong, R., De Jong, S.M., Wulder, M.A., Bater, C.W., Coops, N.C. (2014). Monitoring plant condition and phenology using infrared sensitive consumer grade digital cameras. Agricultural and Forest Meteorology, 184: 98-106. https://doi.org/10.1016/j. agrformet.2013.09.007

[29] Rabatel, G., Gorretta, N., Labbe, S. (2014). Getting simultaneous red and near-infrared band data from a single digital camera for plant monitoring applications: Theoretical and practical study. Biosystems Engineering, 117: 2-14. https://doi.org/10.1016/j.biosystemseng.2013. 06.008

[30] Li, G., Qin, K., Wan, Y.C. (2019). CDIO-OBE mode reformation of remote sensing experiment teaching under the background of emerging engineering. Bulletin of Surveying and Mapping, (6): 140-145,151. https://doi.org/10.13474/j.cnki.11-2246.2019.0203

[31] Wang, L.H., Lu, P. (2018). Teaching Reform Exploration and Practice in the Course of Microwave Remote Sensing. Bulletin of Surveying and Mapping, (10): 140-143,151. https://doi.org/10.13474/j.cnki.11-2246.2018.0333

[32] Friedrich, R.L., Blystone, R.V. (1998). Internet teaching resources for remote sensing and GIS. BioScience, 48(3):187-192. https://doi.org/10.2307/1313264

[33] Van Holsbeeck, S., Srivastava, S.K. (2020). Feasibility of locating biomass-to-bioenergy conversion facilities using spatial information technologies: A case study on forest biomass 
Paper-Teaching of Remote Sensing Technology for Landscape Architecture in the Context of Spatial ...

in Queensland, Australia. Biomass and Bioenergy, 139: 105620. https://doi.org/10.1016 /j.biombioe.2020.105620

[34] Pullar, D.V., Tidey, M.E. (2001). Coupling 3D visualisation to qualitative assessment of built environment designs. Landscape and Urban Planning, 55(1): 29-40. https://doi.org /10.1016/S0169-2046(00)00148-1

[35] Amer, M., Aboelsoud, H., Omar, E.S. (2018). Assessment the Impact of Shallow Groundwater on Soil Salinity and Biomass Yield of Plants Grown in North Nile Delta Using Remote Sensing and GIS Techniques. Egyptian Journal of Soil Science, 58(1): 57-71. https://doi.org/10.21608/ejss.2017.1909.1135

[36] Smith, M.K., Vinson, E.L., Smith, J.A., Lewin, J.D., Stetzer, M.R. (2014). A campus-wide study of STEM courses: New perspectives on teaching practices and perceptions. CBELife Sciences Education, 13(4): 624-635. https://doi.org/10.1187/cbe.14-06-0108

[37] Major, J., Smith, C., Mackay, R. (2018). Reconstructing landscape: Archaeological investigations of the royal exhibition buildings western Forecourt, Melbourne. International Journal of Historical Archaeology, 22(1): 43-66. https://doi.org/10.1007/s10761-017-0414$\underline{5}$

[38] Nagabhatla, N., Kühle, P. (2016). Tropical Agrarian Landscape Classification using highresolution GeoEYE data and segmentationbased approach. European Journal of Remote Sensing, 49(1): 623-642. https://doi.org/10.5721/EuJRS20164933

\section{Authors}

XueLing Zhang is $\mathrm{PhD}$, and lecturer at School of Architecture and Urban Planning, Beijing University of Civil Engineering and Architecture, Beijing 100044, China. Email: zhangxueling@bucea.edu.cn

DaYu Zhang is PhD, and Professor at School of Architecture and Urban Planning, Beijing University of Civil Engineering and Architecture, Beijing 100044, China. Email: zhangdayu@bucea.edu.cn

Article submitted 2021-06-18. Resubmitted 2021-07-19. Final acceptance 2021-07-23. Final version published as submitted by the authors. 